\title{
Changes in tactical behavior during small-sided and conditioned games performed within a training session
}

\section{Mudança no comportamento tático durante uma sessão de treinamento com pequenos jogos}

\author{
Gibson Moreira Praça ${ }^{\top}$ \\ (i) https://orcid.org/0000-0001-9971-7308 \\ Gustavo Fernandes Barbosa ${ }^{1}$ \\ (D) https://orcid.org/0000-0002-3580-0660 \\ Pedro Emilio Drumond Moreira ${ }^{1}$ \\ (D) https://orcid.org/0000-0003-1753-3391 \\ Raphael Brito e Sousa ${ }^{\top}$ \\ (D) https://orcid.org/0000-0003-2692-0289 \\ Sarah Glória Teles Bredt ${ }^{1}$ \\ (D) https://orcid.org/0000-0003-1014-9434 \\ Mauro Heleno Chagas ${ }^{1}$ \\ (D) https://orcid.org/0000-0002-1955-8990 \\ Juan Carlos Pérez Morales ${ }^{1}$ \\ (D) https://orcid.org/0000-0002-4497-5518 \\ Pablo Juan Greco ${ }^{1}$ \\ (D) https://orcid.org/0000-0003-2607-5935 \\ Daniel Memmert ${ }^{2}$ \\ (D) https://orcid.org/0000-0002-3406-9175
}

Abstract - This study aimed to verify the acute effects of 3vs.3 soccer small-sided and conditioned games (SSCG) on the tactical behavior of youth soccer athletes within one training session. Twenty-four soccer athletes (U-13 and U-14 categories) from a professional club participated in the study. They played four 4-minute 3vs.3 SSCG with 4 minutes of passive recovery in-between. All SSCG were recorded and players' tactical behavior was analyzed using the System of Tactical Assessment in Soccer. We compared the frequencies and percentages of successful tactical principles over the four 3vs.3 SSCG bouts performed within the training session. Results showed an increased number of defensive unity actions ( $p=0.005$; large effect size) and a higher percentage of successful defensive principles ( $<<0.001$; moderate effect size) in the fourth bout. We can conclude that players' tactical behaviors change over the SSCG bouts performed within one training session. This suggests that players adapt their tactical behavior according to the tactical problems presented in the SSCG performed within the training session. We can suggest that the long-term improvement in the tactical skills of soccer athletes may be based on these small acute changes in tactical behavior observed in each training session.

Key words: Exercise; Soccer; Sports; Task performance and analysis.

Resumo - O objetivo do estudo foi verificar o efeito do pequeno jogo 3 vs. 3 sobre o comportamento tático de jovens jogadores de futebol em uma sessão de treinamento. Participaram do estudo 24 jogadores das categorias sub-13 e sub-14 de um clube professional. Realizaram-se quatro séries de quatro minutos do pequeno jogo 3 vs. 3 com quatro minutos de pausa passiva entre as séries. Todos os jogos foram filmados $e$ analisou-se o comportamento tático por meio do Sistema de Avaliação Tática no Futebol. Foram comparados a frequência e o percentual de acertos dos princípios táticos nas quatro séries dentro de uma sessão de treinamento. Os resultados evidenciaram aumento do número das açôes de unidade defensiva $(p=0.005$; tamanho do efeito grande) e do percentual de acerto dos princípios defensivos ( $p<0.001$; tamanho do efeito moderado). Conclui-se haver mudança do comportamento tático durante as séries de pequenos jogos realizados dentro de uma sessão de treinamento. Sugere-se que os jogadores adaptam seus comportamentos conforme os problemas táticos emergentes nos pequenos jogos. Além disso, sugere-se que a melhoria da capacidade tática de jogadores de futebol possa se basear nestas pequenas mudanças agudas do comportamento tático observadas dentro de cada sessão de treinamento.

Palavras-chave: Análise e desempenho de tarefas; Esporte; Exercício; Futebol.
1 Universidade Federal de Minas Gerais. Belo Horizonte, MG. Brazil.

2 German Sport University. Köln, Germany.

Received: January 23, 2020 Accepted: March 17, 2020

How to cite this article Praça GM, Barbosa GF, Moreira PED, Sousa RB, Bredt SGT, Chagas MH, Morales JCP, Greco PJ, Memmert D. Changes in tactical behavior during small-sided and conditioned games performed within a training session. Rev Bras Cineantropom Desempenho Hum 2020, 22:e71126. DOI: http://dx.doi. org/10.1590/1980-0037.2020v22e71126

Copyright: This work is licensed under a Creative Commons Attribution 4.0 International License. 


\section{INTRODUCTION}

Match analysis as a methodological approach in sports science has progressively grown, based on the development of different technological systems, like Global Positioning System (GPS) ${ }^{1}$ and the development of observational tools, such as the System of Tactical Assessment in Soccer $(\text { FUT-SAT })^{2}$. The use of these tools during the training process has been increasing the quality of training prescription since it allows coaches to better comprehend the expected impact of different tasks on players' responses. For this reason, different studies are nowadays focused on understanding players' performance in game-like situations (in both training and competition scenarios), such as the small-sided and conditioned games (SSCG). SSCG are commonly used in soccer tactical training oriented by game-based approaches ${ }^{3}$, such as the nonlinear pedagogy $y^{4}$. These approaches suggest that the long-term improvement in players' tactical skills are highly related to the characteristic of the tasks (i.e. SSCG) performed during the training process ${ }^{5}$, which highlights the importance of an appropriate choice of SSCG according to players' needs. Different formats SSCG, such as the 3vs.3, 4vs4 and 5vs5, can provide very specific physical and tactical stimulus (i.e. tactical principles) ${ }^{6}$ and are regularly investigated in the literature ${ }^{7}$. An important issue regarding this SSCG is the possibility to increase the number of tactical actions with the ball (e.g. penetration actions) performed by each player in comparison to SSCG with a higher number of players, such as $5 \mathrm{vs} .5$ and $6 \mathrm{vs} .6^{8,9}$. Although the higher incidence of a specific principle may not be associated with a higher quality of the execution, the propensity of a SSCG for a specific principle may indicate its potential for, in the long-term, developing players' ability regarding that specific principle. The higher number of with-ball actions could increase players' decision-making demand and, consequently, acutely increase performance during the SSCG (i.e. within a session).

Previous studies have shown that players increase their tactical skills by systematically playing SSCG during the training process. Práxedes et al. ${ }^{4}$ showed that U-12 soccer players improved their decision-making after fourteen training sessions with SSCG. According to the authors, the tactical similarity between the formal soccer game and the SSCG may be a possible explanation for the results. The regular exposure to the different tactical problems emphasized during the SSCG may lead to long-term improvement in players' tactical skills due to their adaptive behavior within each training session ${ }^{4}$. Therefore, the accumulation of acute adaptations in tactical behavior is responsible for increasing players' tactical knowledge and chronic changes in tactical behavior. Although some authors have suggested that players' physical and physiological responses change over the SSCG bouts performed within a training session ${ }^{9-12}$, there is no information available on the possible intra-session changes on players' tactical behavior. We expect players to adapt their tactical behavior over the bouts of SSCG performed within the same training session, according 
to the technical-tactical constraints presented in the SSCG performed. The lack of information on the acute changes in tactical behavior during SSCG limits the understanding of the causes of the long-term changes in tactical behavior reported in previous studies.

As previously mentioned, the 3vs.3 SSCG increases players' engagement in with-ball actions in comparison to SSCG with a greater number of players per team ${ }^{8-9}$. In this sense, in SSCG with a lower number of players (e.g. 3vs.3) and smaller absolute playing areas in comparison to the formal game, there is a higher frequency of penetration actions and greater proximity to the opposing goal. These factors stimulate the defending team to increase the level of opposition to the ball carrier to quickly recover the ball possession. Thus, we expect that the 3vs.3 SSCG, even in a free-play condition, will constrain the actions of the defenders and induce an acute adaptive behavior. These adaptations will lead to better tactical performance. The System of Tactical Assessment in Soccer ${ }^{6}$ allows the investigation of players' behaviors and tactical performance through the frequency and successful application of different tactical principles in both offense and defense. Previous studies have shown that young players present a lower defensive compared to offensive performance in both transversal ${ }^{13}$ and longitudina ${ }^{14}$ designs. These results indicate the need to adequately design SSCG to induce adaptive behaviors in defense. Considering this rationale and the widely discussed characteristics of the 3vs.3 SSCG, we expect that the 3vs.3 SSCG will stimulate players to improve their defensive performance, leading to an increase in the number of successful defensive actions from the first to the last SSCG bout within a training session. The assessment of the acute effects of playing SSCG on players' tactical behavior may help coaches to perceive when athletes' have understood the logic of the different SSCG. This information may optimize training time by allowing coaches to change SSCG characteristics over the training sessions to emphasize the development of different tactical behaviors.

Considering the aforementioned issues, this study aimed to verify the acute effects of 3vs. 3 soccer SSCG on the tactical behavior of youth athletes by comparing the frequencies and the percentage of successful tactical principles over four 3vs.3 SSCG bouts within one training session. We hypothesized players would increase their percentage of successful tactical principles over the bouts as well as the frequency of defensive principles against the actions of the ball carrier.

\section{METHODS}

\section{Participants}

Data from a pilot study were used to calculate the necessary sample size for reaching $80 \%$ statistical power with an alfa level of $0.05^{13}$. The percentage of successful defensive actions showed the highest coefficient of variation considering four repeated measures (four SSCG) and was used to calculate sample size with the software G*Power 3.17 (Dusseldorf University, 
Dusseldorf, Germany), as recommended in the literature ${ }^{15}$. We found a minimum sample size of eight participants.

Twenty-four young soccer athletes (twelve U-14, mean age $14.3 \pm 0.7$ and twelve U-13, mean age $13.1 \pm 0.6$ ) from a soccer club participated in the study. Inferential statistical analyses showed no differences in tactical behavior between categories, therefore, we analyzed U-13 and U-14 athletes as one group. These athletes participated in regional level competitions organized by the state soccer federation. All athletes presented medical clearance for participating in the study. This study was approved by the local ethics committee (CAE 64639417.0.0000.5149). Both athletes and their legal guardians were informed of the research procedures and gave written consent to participate in the study. We followed all the principles outlined in the Declaration of Helsinki.

\section{Design and Procedures}

Firstly, we divided players of each category into teams to play the 3vs.3 SSCG. Previous studies have shown that tactical behavior in soccer SSCG can be influenced by various criteria of team composition ${ }^{16-17}$. In this study, we divided the twelve players of each category into four teams, each one with a defender, a forward, and a midfielder, to reduce the influence of the playing position on the observed behavior ${ }^{18}$. In addition, a previous study has shown that players show a better tactical performance during soccer SSCG when the teams are balanced according to players' tactical knowledge $^{17}$. Therefore, on the first day, we used the FUT-SAT test ${ }^{6}$ to assess players' tactical knowledge and form balanced teams. The percentage of successful tactical principles in this test was used to form two groups (i.e., groups 1 and 2) within each playing position. Each group was composed of the two players of each position with the highest and lowest performances. The teams were formed within each group, consisting of a defender, a midfielder, and a forward (see Table 1). The teams of group 1 did not play against teams of group 2 . The same procedures were performed within the $\mathrm{U}-13$ and $\mathrm{U}-14$ categories.

Table 1. Teams' composition.

\begin{tabular}{llllllll}
\hline \multicolumn{4}{c}{ GROUP 1 } & \multicolumn{5}{c}{ GROUP 2 } \\
\hline Team A & $\mathrm{d} 1$ & $\mathrm{~m} 2$ & $\mathrm{f1}$ & Team C & $\mathrm{d} 3$ & $\mathrm{~m} 4$ & $\mathrm{f3}$ \\
Team B & $\mathrm{d} 2$ & $\mathrm{~m} 1$ & $\mathrm{f2}$ & Team D & $\mathrm{d} 4$ & $\mathrm{~m} 3$ & $\mathrm{f4}$ \\
\hline
\end{tabular}

Notes. A, B, C, D: teams within each category. d: defender; m: midfielder; f: forward; 1, 2, 3, 4: individual classification in the rank of percentage of successful actions, where 1 and 4 indicates best and worst performance in FUT-SAT, respectively.

On the second day, we carried out a familiarization session with the SSCG. On the following two days, the athletes completed the four bouts of 3vs.3 SSCG on a 36x27meter playing field. All soccer rules were included in the SSCG, except for the throw-ins, which were performed only with the feet to quickly restart the game after the ball went out of play. Each SSCG bout lasted 4 minutes, interspersed with 4 minutes of passive rest. 
Coaches and researchers did not give the athletes any feedback during the SSCG. All SSCG were performed at the beginning of the regular training session, after a 10-minute warm-up.

\section{Measures}

The FUT-SAT, which was also used for the teams' composition, consists of a 4-minute 3vs. 3 game with goalkeepers played in a 36x27meter playing field and $6 \times 2$-meter goals ${ }^{6}$. It allows the assessment of the frequencies of the core tactical principles. There are five principles related to offense (penetration, offensive coverage, depth mobility, width and length with and without the ball, and offensive unity) and five related to defense (delay, defensive coverage, balance, concentration, and defensive unity). The percentage of successful tactical principles (ratio between the number of successful tactical principles and the total number of tactical principles performed) in offense and defense was used as a measure of tactical performance ${ }^{17}$.

The FUT-SAT test was recorded with a digital camera (JVC, Kenwood, USA). Two expert analysts trained in the use of FUT-SAT analyzed the recordings and observed players' tactical behavior with the software Soccer Analyser ${ }^{\circledR}$. This software allows the insertion of a field diagram upon the video image and establishes the offensive and defensive fields, the lateral and central corridors, the game center and the ball line, which are the references adopted for the definition of the tactical principles. One SSCG (4 bouts - 16,6\%, higher than the $10 \%$ recommended) was reanalyzed to verify reliability within and between observers ${ }^{19,20}$. The Kappa of Cohen reliability coefficients were 0.89 (95\% CI 0.86-0.91) and 0.94 (95\% CI 0.93-0.95) for between and within-observer agreements, respectively.

\section{Statistical Analysis}

The frequencies of each fundamental tactical principle and the percentage of successful principles performed per player in each SSCG bout were expressed as median and interquartile amplitude. The comparison between bouts was performed using the Friedman test (non-parametric analysis of variance for repeated measurements) and Dunn's post hoc (GraphpadPrism-GraphPad Software Inc., CA, USA). Effect sizes r were calculated to characterize the magnitude of the differences between bouts and classified as small $(r<0.1)$, medium $(0.1<r<0.3)$, or large $(r>0.3)^{21}$. The statistical significance has been set at $5 \%$.

\section{RESULTS}

Table 2 shows the medians (interquartile amplitudes) of the frequencies of each fundamental tactical principle performed per player in each bout. There were significant differences between bouts for defensive unity $(p=0.005)$, with large effect sizes between the fourth and the first (adjusted $p=0.02$, $r=0.38$ ) bouts and the fourth and the second bouts (adjusted $p=0.05, r=$ $0.37)$. Large effect size was found between the third and the first bouts $(r=$ 
$0.34)$, although their frequencies were not statistically significant $(p=0.23)$. In general, the results indicate a tendency towards an increase in defensive unity actions over bouts. All the other principles showed no significant differences between bouts for paired comparisons (Dunn's post hoc).

Table 2. Median (interquartile amplitude) of the frequencies of each fundamental tactical principles per player in each SSCG bout.

\begin{tabular}{|c|c|c|c|c|c|}
\hline & & Bout 1 & Bout 2 & Bout 3 & Bout 4 \\
\hline \multirow{6}{*}{ 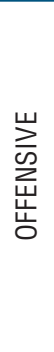 } & Penetration & $3.00(2.00-4.00)$ & $3,50(2.00-5.75)$ & $4.00(2.25-5.00)$ & $3.50(2.00-4.00)$ \\
\hline & Offensive Coverage & $4.00(3.00-6.00)$ & $6.00(3.00-6.75)$ & $4.00(3.00-5.75)$ & $4.00(4.00-6.00)$ \\
\hline & $\begin{array}{l}\text { Width and Length } \\
\text { without ball }\end{array}$ & $10.00(9.00-12.00)$ & $11.00(9.00-15.5)$ & $9.00(6.00-12.5)$ & $9.00(8.00-11.00)$ \\
\hline & $\begin{array}{l}\text { Width and Length with } \\
\text { ball }\end{array}$ & $2.00(1.00-3.00)$ & $1.50(1.00-3.00)$ & $1.00(1.00-2.00)$ & $1.00(1.00-2.00)$ \\
\hline & Mobility & $1.00(0.00-2.75)$ & $2.00(2.00-4.00)$ & $1.50(1.00-2.75)$ & $1.50(1.00-2,75)$ \\
\hline & Offensive Unity & $4.00(2.25-6.00)$ & $4.00(2.25-5.75)$ & $5.00(4.00-8.00)$ & $5.00(4.00-75)$ \\
\hline \multirow{6}{*}{$\begin{array}{l}\text { 岕 } \\
\text { 岀 } \\
\text { 㟧 }\end{array}$} & Delay & $6.00(4.00-7.75)$ & $8.00(6.00-10.75)$ & $5.50(4.00-8.75)$ & $5.50(4.00-6.75)$ \\
\hline & Defensive Coverage & $1.50(1.00-2.00)$ & $1.00(1.00-2.75)$ & $1.00(0.00-1.00)$ & $1.00(0.00-2.00)$ \\
\hline & Defensive Balance & $6.00(4.25-8.75)$ & $7.00(4.00-10.00)$ & $4.00(3.00-7.75)$ & $4.00(3.00-6.75)$ \\
\hline & Recovery Balance & $2.50(1.00-4.00)$ & $2.00(1.00-3.00)$ & $2.00(1.00-3.75)$ & $2.00(1.00-4.00)$ \\
\hline & Concentration & $3.50(2.25-4.75)$ & $4.00(2.00-6.00)$ & $3.00(2.00-5.00)$ & $3.00(2.00-4.00)$ \\
\hline & Defensive Unity & $8.00(7.00-10.75)$ & $9.00(7.00-10.00)$ & $11.50(7.25-14.75)$ & $12.50(9.00-14.75)^{*}$ \\
\hline
\end{tabular}

Notes. * indicate significant difference compared to the other bouts.

Figure 1 shows the medians ( $95 \%$ confidence intervals) of the percentage of successful offensive and defensive fundamental tactical principles. The fourth bout presented a significantly higher percentage of successful defensive tactical principles $(\mathrm{p}<0.001$, moderate effect) than the first and second bouts.

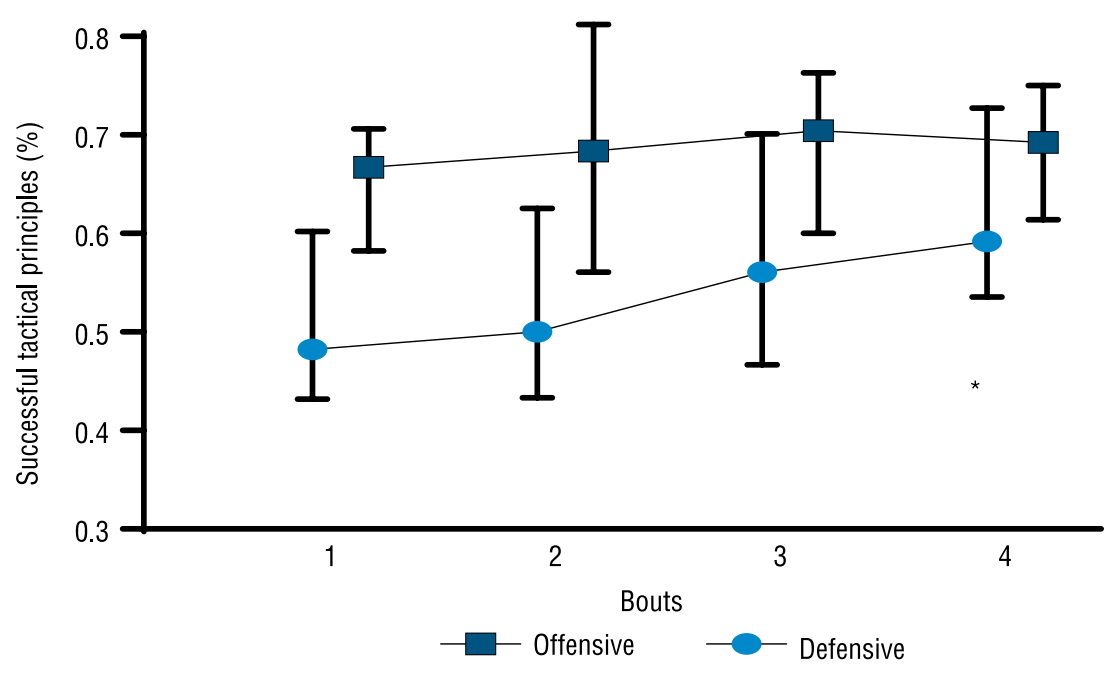

Figure 1. Median of the percentage of successful tactical principles per player in defense and offense in each SSCG bout. * indicate significant difference compared to bouts 1 , and 2.

\section{DISCUSSION}

The use of SSCG for tactical training in soccer is supported by its potential 
to emphasize the learning of specific behaviors, by implementing different task-constraints in the SSCG. However, there is no information on the acute effects of playing SSCG on players' tactical behavior, which could help to explain the long-term tactical development found in previous studies. Our study aimed to investigate the acute changes in youth athletes' tactical behavior and performance induced by four bouts of 3vs.3 soccer SSCG. We hypothesized that players would change their behavior over the SSCG bouts performed within the same training session and increase their percentage of successful defensive actions. These hypotheses were confirmed by the results.

The results of this study showed significant differences in the defensive tactical behavior over the SSCG bouts and showed an increase in the frequency of defensive unity actions in the last bout. These data suggest that the defenders attempted to reduce attackers' effective playing space and their actions to create numerical equality or superiority in the lateral zones of the game center over the SSCG bouts. Silva et al. ${ }^{22}$ found higher frequencies of defensive unity and defensive balance (both defensive and recovery balance analyzed together) for winning teams of 3vs.3 SSCG, which partially corroborates our results. A higher frequency of defensive unity may suggest that players who won the SSCG had a better space occupation in defense. Therefore, the changes in athletes' tactical behavior found in our study may be a consequence of players' adaptation to the SSCG taskconstraints, leading to better recognition of opponents' movement patterns from the beginning to the end of the same training session. Finally, in the fourth bout, there was an increase in the percentage of successful defensive principles (defensive performance) compared to the other three bouts. The increased perception of the movement patterns of the offensive players also supports this result, leading to an improvement in players' positioning and an increase in the successfulness of defense. In summary, the changes in players' behavior within the same training session does not seem to be random, since the behaviors observed in the last SSCG bout represent a better way to manage space and time during the SSCG. Although these results may be insufficient to describe the learning process of tactical skills (which would demand a different study design and retention tests), they provide an insight on the within-session variability of tactical behavior and on the small changes that may build up long-term tactical learning.

Concerning the offensive tactical behavior, the results showed no differences between bouts for the percentage of successful tactical principles. The main explanation for this result may be the usual focus on with-ball actions during the training process instead of defensive positioning skills. Indeed, previous studies reported a higher offensive than defensive tactical performance over the season ${ }^{17}$, which gives support to the aforementioned hypotheses. In the present study, players presented a higher offensive compared to defensive performance, which is in line with the previously mentioned study. Therefore, a possible explanation for the lack of improvement in the offensive performance within the SSCG training session may be related to athletes' high initial scores. The higher offensive performance 
may present a reduced possibility to increase within one training session. Therefore, four SSCG bouts may have not been enough to change the offensive tactical performance, since they already presented high offensive skills. It is important to highlight that previous studies found some contrasting results. Dellal et al. ${ }^{23}$ found a lower percentage of correct passes and a lower frequency of duels from the first to the fourth bout of $4 \mathrm{vs.} 4$ SSCG. In addition, Kelly and Drustheight found lower dribbling and shooting frequencies in the last three compared to the first bout of $5 \mathrm{vs.5}$ SSCG. The authors explained these results by the influence of fatigue on offensive behavior, which could have reduced the total number of goal attempts and the frequency of offensive tactical principles. Although our study did not examine players' physical nor physiological responses, we used a longer rest interval ( 4 minutes) between bouts compared to these previous studies ( 2 or 3 minutes). Therefore, we reduced the likelihood of a negative impact of fatigue on tactical performance, which could explain the different results.

The results of this study suggest that a higher number (more than four) of SSCG bouts within a training session may be necessary to induce players' better recognition of tactical patterns during 3vs.3 SSCG and, consequently, improve their tactical behavior within the same training session (although this isn't obviously the only factor impacting players' tactical behavior). This suggestion may be supported by the lack of an increase in the defensive unit until the fourth bout (rest intervals may require adjustments to avoid the negative influence of fatigue on the tactical behavior after several bouts). Other SSCG may be necessary to stimulate acute improvements on the tactical performance of other principles. Although our data are possibly limited to the athletes investigated in this study (regarding their specific characteristics of tactical behavior and performance and its dependence on the club training process - i.e., training contents, methods, and sequence) and the characteristics of the SSCG investigated, they support the potential use of SSCG for the development of tactical skills in youth athletes. The long-term improvement in tactical performance may be related to the small acute changes observed within each training session. Future studies should investigate the within-session variation during play of different SSCG and how the acute changes in tactical behavior may shape the long-term improvement (i.e. learning) of players' tactical skills. Finally, considering that the FUT-SAT provides the analysis of the frequency of tactical principles, the variability in tactical-technical performance during the game may not be fully captured with this instrument. Therefore, other instruments should be developed for the analysis of players' tactical actions within a context with variable (non-linear) performance, like soccer.

Besides the abovementioned impacts of the current study on talent development in soccer, this study provides interesting information about the process of talent detection within youth academies. Specifically, when selecting players, coaches and scouts usually make their observations during a short period, in which it is expected that the players present their full 
potential. However, based on the current study, seems reasonable to suggest that providing players with more practice time allows them to adapt to the context and fully demonstrate their potential. So, avoiding immediate and short-time assessments is a desirable pathway for the talent identification process in youth academies. Future research should focus on more theoretical modelling ${ }^{24}$ and $11 \mathrm{v} 11$ game scenarios ${ }^{25}$.

\section{CONCLUSION}

We conclude that players adapt their behavior within the bouts of small-sided games. It is also concluded that these adaptations are likely to be observed in tactical principles in which the initial performance is lower, often the defensive ones. Finally, these findings may be on the basis of the long-term development of tactical skills, previously reported in the literature to be a result of the engagement in sport-specific training programs with game-based tasks.

\section{Acknowledgments}

We thank Clube Atlético Mineiro for participating in the study and supporting the data collection.

\section{Funding}

We thank FAPEMIG, CAPES, and Pró-reitoria de Pesquisa of Universidade Federal de Minas Gerais for their financial support.

\section{Ethical approval}

Ethical approval was obtained from the Institutional Ethics Board - Universidade Federal de Minas Gerais and the protocol 64639417.0.0000.5149 was written in accordance with the standards established by the Declaration of Helsinki.

\section{Conflict of interest statement}

The authors have no conflict of interests to declare.

\section{Author Contributions}

Conception and design of the experiment: GFB, PEDM, RBS, SGTB, MHC, JCPM, GMP, PJG e DM. Realization of the experiments: GFB, PEDM, RBS, GMP. Data analysis: GFB, PEDM, SGTB, MHC, JCPM, GMP. Contribution with reagents/research materials/analysis tools: GFB, PEDM, RBS, SGTB, MHC, JCPM, GMP, PJG and DM. Article Writing: GFB, PEDM, RBS, SGTB, MHC, GMP and DM. All authors read and approved the final version of the manuscript.

\section{REFERENCES}

1. Sarmento H, Clemente FM, Araújo D, Davids K, McRobert A, Figueiredo A. What Performance Analysts Need to Know About Research Trends in Association Football (2012-2016): A Systematic Review. Sport Med 2018;48(4):799-836. 
2. Padilha MB, Guilherme J, Serra-Olivares J, Roca A, Teoldo I. The influence of floaters on players' tactical behaviour in small-sided and conditioned soccer games. Int J Perform Anal Sport 2017;17(5):721-736.

3. Serra-Olivares J, Gonzalez-Villora S, Garcia-Lopez LM, Araujo D. Game-Based Approaches' Pedagogical Principles: Exploring Task Constraints in Youth Soccer. J Hum Kinet 2015; 46(1):251-261.

4. Práxedes A, Del Villar F, Moreno A, Gil-Arias A, Davids K. Effects of a nonlinear pedagogy intervention programme on the emergent tactical behaviours of youth footballers. Phys Educ Sport Peda 2019; 24:1-12.

5. Práxedes A, Del Villar F, Pizarro D, Moreno A. The Impact of Nonlinear Pedagogy on Decision-Making and Execution in Youth Soccer Players According to Game Actions. J Hum Kinet 2018; 62:185-198.

6. Teoldo I, Garganta JM, Greco PJ, Mesquita I, Maia J. System of tactical assessment in Soccer (FUT-SAT): Development and preliminary validation. Motrici 2011; 7(1):69-83.

7. Sarmento H, Clemente FM, Harper LD, Teoldo I, Owen A, Figueiredo, AJ. Small sided games in soccer - a systematic review. Int J Perf Anal Spor 2018; 18(5):693-749.

8. Castelão D, Garganta J, Santos R, Teoldo I. Comparison of tactical behaviour and performance of youth soccer players in 3v3 and 5v5 small-sided games. Int J Perf Anal Spor 2014; 14(3):801-813.

9. Silva B, Garganta J, Santos R, Teoldo I. Comparing Tactical Behaviour of Soccer Players in 3 vs. 3 and 6 vs. 6 Small-Sided Games. J Hum Kinet 2014; 41:191-202.

10. Clemente FM, Nikolaidis PT, Van Der Linden CMIN, Silva B. Effects of SmallSided Soccer Games on Internal and External Load and Lower Limb Power: A Pilot Study in Collegiate Players. Hum Mov 2017; 18(1):50-57.

11. Kelly DM, Drust B. The effect of pitch dimensions on heart rate responses and technical demands of small-sided soccer games in elite players. J Sci Med Sport 2009; 12(4):475-479.

12. Köklü Y, Aşçi A, Koçak FU, Alemdarođlu U, Dündar U. Comparison of the physiological responses to different small-sided games in elite young soccer players. J Strength Cond Res 2011;25(6):1522-1528.

13. Reis MAM, Vasconcellos FVA, Almeida MB. Performance and tactical behavior of youth soccer players. Rev Bras Cineantropom Desempenho Hum 2017; 19(2):242-250.

14. Praça GM, Morales JCP, Bredt SDGT, Sousa RBE, Andrade AGPD, Greco PJ. The development of tactical skills in U-14 and U-15 soccer players throughout a season: A comparative analysis. Hum Mov 2017;18(5):39-47.

15. Beck TW. The importance of a priori sample size estimation in strength and conditioning research. J Strength Cond Res 2013;27(8):2323-2337.

16. Köklü Y, Ersöz G, Alemdaroglu U, Asxcxi A, Özkan A. Physiological responses and time-motion characteristics of 4-A-side small-sided game in young soccer players: The influence of different team formation methods. J Strength Cond Res 2012;26(11):3118-3123.

17. Praça GM, Morales JCP, Moreira PED, Peixoto GHC, Bredt ST, Chagas MH, et al. Tactical behavior in soccer small-sided games: influence of team composition criteria. Rev Bras Cineantropom Desempenho Hum 2017;19(3):354-363.

18. Praça GM, Clemente FM, Andrade AGP, Morales JCP, Greco PJ. Network analysis in small-sided and conditioned soccer games: The influence of additional players and playing position. Kinesiology 2017;49(2):185-193.

19. Robinson $\mathrm{G}$, O'Donoghue PG. A weghted kappa statistic for reliability testing in performance analysis of sport. Int J Perf Anal Spor 2007;7(11):12-19.

20. Tabachnick B, Fidell L. Using multivariate statistics. New York: Harper and Row Publishers; 1989.

21. Field, A. Discovering Statistics Using Spss. 3Ed. London: SAGE Publications; 2009. 
22. Silva RNB, Costa IT, Garganta JM, Muller ES, Castelão DP. Tactical performance of youth soccer players: comparison between winners and losers teams in small sized games. Rev Bras Ciênc Mov 2013; 21(1):75-89.

23. Dellal A, Lago-Peñas C, Wong DP, Chamari K. Effect of the number of ball contacts within bouts of 4 vs. 4 small-sided soccer games. Int J Sport Physiol 2011;6(3):322-333.

24. Rein R, Memmert D. Big data and tactical analysis in elite soccer: future challenges and opportunities for sports science. SpringerPlus 2016;5(1):1410

25. Memmert D, Raabe D, Schwab S, Rein R. A Tactical Comparison of the 4-2-3-1 and 3-5-2 Formation in Soccer: A Theory-Oriented, Experimental Approach Based on Positional Data in an 11 vs. 11 Game Set-Up. PloS ONE 2019;14(1):e0210191.

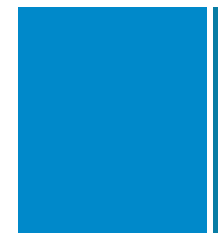

Corresponding author

Gibson Moreira Praça

Universidade Federal de Minas Gerais. Escola de Educação Física,

Fisioterapia e Terapia Ocupacional. Departamento de Esportes.

Av. Presidente Antônio Carlos, 6627. Campus Pampulha. CEP 31270-901.

Belo Horizonte, Minas Gerais, Brazil.

E-mail: gibson_moreira@yahoo.com.br 